\title{
THE DEVIL'S CHILDREN: FROM SPIRIT POSSESSION TO WITCHCRAFT: NEW ALLEGATIONS THAT AFFECT CHILDREN Edited by Jean La Fontaine
}

Reviewed by Harold Wanton

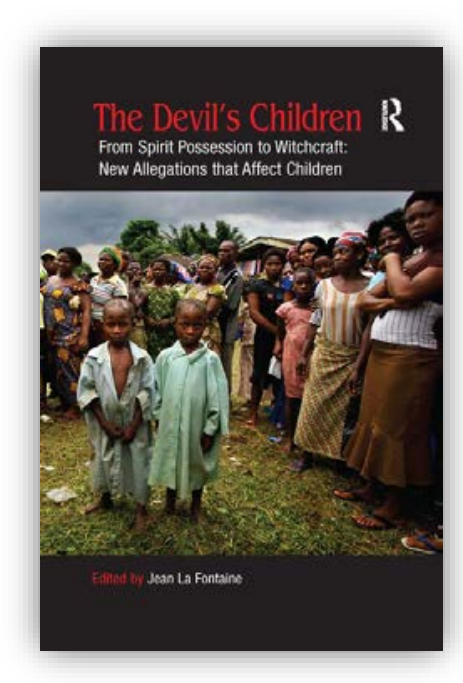

New York: Routledge

2009

In The Devil's Children: From Spirit Possession to Witchcraft: New Allegations that Affect Children, various authors articulate the issue of child abuse and its association with possession and witchcraft. For centuries there have been a multitude of scientific and religious justifications for such abuse despite the obscurity of possession, witchcraft and/or black magic. The Devil's Children contains contributions from academics and practitioners representing numerous fields. Jean La Fontaine's edited collection's purpose is to fill a substantial void in the contemporary literature on spirit possession as it relates to child abuse. Allegations and cases of child abuse are not always correlated to the idea of children being possessed. However, some cases of possession have been linked to children being severely injured or killed and have garnered public attention.

La Fontaine divides the body of work into three sections: the meaning of possession, possession as contact with the divine, and cases where the belief in possession acted as an indication of children being "witches" which resulted in child abuse. In Part One of the text, "The Meaning of Possession," contributors delineate the history of spirit possession in various religions in order to posit "how beliefs in possession may have different meanings and effects in different religious contexts" (27). Part Two, "Possession as Contact with the Divine," gives positive examples of "voluntary possession", found in Christianity and Wicca as a means of a greater connection to the divine. Part Three, "Children Accused," examines specific cases where accusations of witchcraft have been made against children which resulted in abuse, and in some cases death.

The Devil's Children provides key knowledge of different religious and ethnic communities' outlooks on possession. Interestingly, Children accused of possession or witchcraft are closely linked to familial misfortune. The work of Robert J. Priest, Abel Ngolo, and Timothy Stabell (2020), in many ways, mirrors the findings of this book in their dealing with Christian pastors and (alleged) child witches in Kinshasa, DRC. Their work presents the horrendous reality of the stamp of being labeled a "witch" or "possessed" and the eventual repercussions of it. The chapter contributed by La Fontaine in his edited volume describes the belief in possession linked to newly arrived immigrants and the economically marginalized. In Priest et al., these misfortunes are similar but not reduced to just those factors.

One of the strengths of this book is that it contributes to the eclectic study of possession not solely in a religious context nor an anthropological framework. Its contributors articulate a variety of unbiased, participatory approaches that make the text one of a kind. The work offers interreligious justifications of what "spirit possession" is and its influence within communities. La Fontaine's contributors do not only offer the reader a new awareness that cases of child abuse are due to accusations of spirit possession or witchcraft, they also identify the patterns of child abuse 
in hopes of prevention. Another strength of this text is its comparative approach which offers readers religious or geographical commonalities. One of the weaknesses of this work is that it is a product of its own uniqueness. In some ways the work is waiting to be expounded upon theoretically due to the lack of research and information previously conducted on the subject.

As Christians, we must understand that children are a gift and we must rejoice in them and preserve them because they are God's gift to the earth. "Take heed that you do not despise one of these little ones, for I say to you that in heaven their angels always see the face of my Father" (Matthew 18:10). Children are in a fertile moment for growth, and any abuse harms them mentally and physically, and affects their growth in the community of the Church. Therefore, the abuse or death of children either inside or outside the safeguards of the Church due to accusations of "possession" has to be investigated to preserve the holiness of Christ's Body.

A Christian anthropological perspective would engage in the realm of spirit possession and witchcraft with heightened knowledge of Christian theological perspectives and the different variations of cultures that deal with the two terms. In this respect, Christian anthropologists would exemplify how spirit possession and witchcraft is inwoven into the cultural fabric of specific groups of people and how this affects converting to Christianity. In this, the understanding of prevention of child abuse will be articulated in such a way that it does not disrespect believers' cultural traditions and beliefs but presents the religious understanding that is needed to effectively change patterns.

The Devil's Children is a substantially important text for scholars, and it explores uncharted areas of study. Professional scholars and practitioners will benefit from this body of work and it provides readers with a greater understanding of what possession means and what its effects are within the contemporary world.

\section{Reference}

Priest, Robert J., Abel Ngolo and Timothy Stabell. 2020. Christian Pastors and Alleged Child Witches in Kinshasa, DRC. On Knowing Humanity Journal 4(1):1-51.

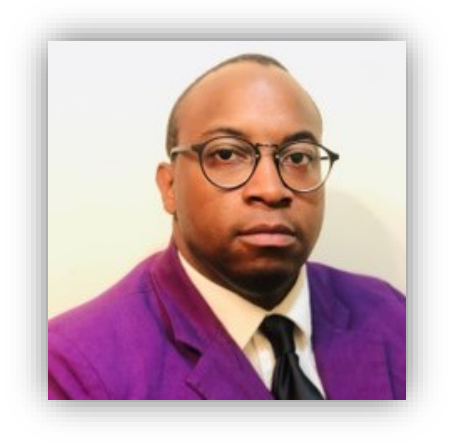

Harold Wanton is currently pursuing a master's degree in Theological and Cultural Anthropology at Eastern University, in St. David, Pa. He has research interests in religion, the Ethiopian Orthodox Church and sociolinguistics.

Author email: harold.wanton@eastern.edu 